\title{
O estudante de Medicina e o médico recém-formado frente à morte e ao morrer
}

\author{
How medical students and recent medical \\ graduates deal with death and dying
}

\author{
Gustavo Nader Marta \\ Sara Nader MartaII \\ Ayrton de Andrea Filho ${ }^{\text {III }}$ \\ José Roberto Pretel Pereira Job ${ }^{\mathrm{III}}$
}

\section{PALAVRAS-CHAVE \\ - Morte \\ - Educação médica \\ - Ética \\ - Bioética}

Recebido em: 05/01/2009 Reencaminhado em: 23/01/2009 Aprovado em: 15/03/2009

REVISTA BRASILEIRA DE EDUCAÇ̃̃O MÉDICA

\footnotetext{
${ }^{I}$ Hospital Sírio-Libanês. Centro de Oncologia do Hospital Sírio-Libanês, São Paulo, São Paulo, Brasil

${ }^{I I}$ Uiversidade do Sagrado Coração, Bauru, São Paulo, Brasil; Associação Paulista de Cirurgiões-Dentistas, São Paulo, São Paulo, Brasil.

IIPontifícia Universidade Católica, Sorocaba, São Paulo, Brasil.

Este trabalho foi realizado com o apoio do Centro de Bioética do Conselho Regional de Medicina do Estado de São Paulo (Cremesp).
} 


\section{INTRODUÇÃO}

Curar às vezes, aliviar muito frequentemente e confortar sempre. Oliver Holme

A medicina se estabelece, muitas vezes, sob um panorama dialético entre as "verdades" instituídas pela ciência e a "boa conduta" debatida pela ética. Essa dualidade suscita questões herméticas que precisam ser discutidas. Sob tal perspectiva, desponta, de forma conspícua, o tema da morte e do morrer, o que evoca a responsabilidade das posturas e condutas frente ao doente terminal ${ }^{1}$.

A literatura científica tem sido perdulária em publicações sobre as atitudes dos profissionais de saúde diante da terminalidade dos pacientes e aponta a existência de vieses em relação ao assunto, que precisa ser desenvolvido de acordo com as peculiaridades de cada sociedade em cada época. Numa sociedade de grandes contrastes culturais e socioeconômicos como a nossa, é importante conhecer o gabarito dos médicos, especialmente recém-formados, para lidar com tais situações.

O presente estudo teve como objetivos: (1) verificar no estudante de Medicina e no médico recém-formado seus posicionamentos e atitudes acerca do morrer e da morte; (2) identificar as condições e deficiências da relação médico-paciente-morrer-morte; (3) comparar tais posturas entre os estudantes de Medicina e os médicos recém-formados; (4) propor atividades que possibilitem a sensibilização dos processos internos, com base em teoria, prática e desenvolvimento pessoal sobre essa temática.

\section{CONSIDERAÇÕES INICIAIS}

A morte é uma das mais autênticas problemáticas da condição humana, tendo demandado diligências para o seu enquadramento ao longo da história do pensamento ocidental ${ }^{2}$. Do ponto de vista filosófico, inúmeros autores discorreram sobre o significado da morte ${ }^{3}$ : a finitude é considerada como instância inalienável à dimensão humana para pensadores como Heidegger $^{4}$ e Montaigne ${ }^{5}$; já Spinosa ${ }^{6}$ Hegel $^{7}$ negam a primazia da finitude como questão primária da existência humana, articulando um discurso com vistas à superação da morte. Mesmo que a reflexão sobre o próprio fim seja irrealizável, o saber-se mortal é um dos espeques da experiência que o homem tem de si mes$\mathrm{mo}^{2}$; ou seja, o homem é determinado pela consciência objetiva de sua mortalidade e por uma subjetividade que almeja a imortalidade $^{8}$.
As atitudes frente à morte alternam-se com as estruturas institucionais, a ideologia, a cultura e os mitos de cada época ${ }^{9}$. Os mitos do início e fim da vida são necessários para engendrar a identidade dos membros de toda e qualquer civilização e cultura, e a maneira pela qual cada uma enfrenta a morte dá sentido ao sofrimento, à dor e à doença ${ }^{10}$. Segundo Morin ${ }^{11}$, é nos atos e crenças diante da morte que o homem manifesta o que a vida tem de mais fundamental.

A sociedade contemporânea labora com a morte por meio da tentativa de suprimi-la de seu cotidiano ${ }^{12,13,14}$. De acordo com Lasch $^{15}$, vivemos na cultura do narcisismo, caracterizada pela dificuldade de discernir o que realmente somos, da fantasia dos produtos que consumimos. Vive-se, portanto, em um mundo "onírico, de impressões e aparências". Escamoteia-se a morte porque ela é a comprovação de nossa finitude, nosso limite ${ }^{16}$.

Paralelamente, tem-se o início do processo de medicalização do morrer e da própria morte. $\mathrm{O}$ tradicional morrer não ocorre mais no leito em domicílio, com o enfermo assistido por familiares e pessoas amigas; passa a acontecer em instituições médicas, tendo como companhia equipamentos e profissionais atarefados. A morte torna-se solitária e, por isso, assustadora ${ }^{17,18,19}$.

Essa parece ser uma organização que contempla a dessacralização e a banalidade da morte, cujas consequências são nocivas $^{20}$ : os ritos de morte são simplificados, a repressão da dor é prescrita em lugar das manifestações outrora usuais ${ }^{21}$, medicaliza-se o luto ${ }^{13,20}$

No contexto hospitalar, o doente e, muitas vezes, a família não têm participação na decisão da morte ${ }^{20}$. Trata-se da morte interdita em que o moribundo parte sem dizer e ouvir nada sobre seu momento final ${ }^{21}$. Ademais, o desenvolvimento da medicina de alta tecnologia transformou a trajetória das doenças: prolongou-se a vida e o processo de morrer. Isso criou um novo modelo médico em que os profissionais têm de cuidar e conviver com pacientes gravemente enfermos, situação muitas vezes acompanhada de árduo sofrimento ${ }^{18,19}$

O médico tornou-se o responsável por combater e vencer a morte; é o ser tanatolítico ${ }^{22}$ (grego: tanatos $=$ morte, litis = destruição) que decide tecnicamente o momento da morte e as circunstâncias do morrer ${ }^{20}$. Dessa maneira, o profissional assume-se como onipotente e prioriza salvar o paciente a qualquer custo a fim de corresponder às expectativas idealizadas de preservador de vidas ${ }^{17}$. No entanto, a ocorrência da morte e de doenças incuráveis solapa tais preceitos, fazendo o médico se defrontar com sua insignificância diante de situações irreversíveis: depara-se consigo mesmo, com a própria finitude, frustrando-se ${ }^{18}$. 
Com efeito, temerosos por esses sentimentos, é no isolamento das emoções que os médicos buscam uma de suas principais defesas contra a angústia. Gera-se a ideologia do distanciamento e da frialdade desumanizadora. A neutralidade, a alienação e a indiferença são ditas sine qua non para o bom desempenho do trabalho, uma vez que afastam o sofrimento do profissional frente à morte do outro e de si mesmo ${ }^{14,20}$.

A formação médica promove a incorporação desse modelo aparentemente racional, não emocional e científico. O estudante de Medicina, no primeiro ano de faculdade, entra em contato com os cadáveres nas aulas de Anatomia. Para Sapir ${ }^{23}$, o defrontar-se com o cadáver inicia os alunos no desenvolvimento dos mecanismos de defesa imprescindíveis à futura profissão. Nesse instante, o discente é confrontado com a morte e passa a acionar suas defesas: inicialmente, esse contato é difícil; aos poucos, o cadáver torna-se objeto de satisfações libidinais ${ }^{24}$, permitindo ao aluno experimentar uma sensação de poder absoluto 9 . Para ele, a busca do conhecimento e a objetividade científica têm a função de aliviar a angústia diante da morte.

Posteriormente, o terceiranista é iniciado na Propedêutica, quando terá o real contato com os doentes, passando a frequentar o ambulatório e o hospital. Acontece uma mudança significativa nesse momento: tem-se que conviver e aprender a lidar com o fato de que o desenvolvimento do aprendizado da medicina se dará por meio da dor, sofrimento e morte dos pacientes ${ }^{17}$. Emerge o que Zaidhaft ${ }^{9}$ denominou situação-limite: o aluno se defronta com a sua própria finitude ao lidar com o vivo que está próximo da morte, o futuro morto.

No internato, os alunos são membros integrantes do corpo médico e vão aprender medicina em situações reais do cotidiano hospitalar. A rotina de suas vivências acadêmicas deixa pouco espaço para os momentos de introspecção. As dúvidas e angústias são muitas, e a autoavaliação é realizada frente ao paciente por meio da capacidade diagnóstico-terapêutica. É a partir daqui que se tem a percepção de que a realidade profissional é muito distorcida e dissuadida da fantasia de cura e controle sobre a vida dos pacientes ${ }^{17}$. Mais do que isso, o futuro médico não tem, na maior parte de sua formação acadêmica, a possibilidade de discutir de modo adequado as suas dúvidas, dores e vivências com profissionais gabaritados, pela insuficiência de conteúdos teóricos na grade curricular e ausência de especialistas para clarear os conceitos e dirimir preconceitos sobre o tema ${ }^{25}$. Assim, na prática, raramente está investido no papel profissional que deverá futuramente desempenhar em situações do morrer e da morte; por conseguinte, a angústia emergirá somente em situações-limite.

\section{MATERIAL E MÉTODOS}

Foram analisadas as respostas dos questionários apresentados a todos os 120 médicos residentes (Grupo 1-R) e aos 100 alunos do terceiro ano (Grupo 2 - A) da Faculdade de Medicina de Sorocaba - Centro de Ciências Médicas e Biológicas da Pontifícia Universidade Católica de São Paulo (CCMB-PUC-SP), de julho a agosto de 2006, com o objetivo de verificar a conduta e as dificuldades enfrentadas por eles diante da morte e do morrer. $\mathrm{O}$ instrumento de avaliação (questionário) foi construído a partir de adaptações dos questionários propostos por Moritz ${ }^{19}$ e D'Assumpção ${ }^{26}$ com a introdução de questões consideradas relevantes para o estudo proposto. Trata-se de um questionário estruturado, autoaplicativo, composto de informações demográficas e 18 perguntas.

A distribuição dos questionários aos participantes e a explicação da pesquisa aos entrevistados se deram após aulas acadêmicas e reuniões científicas. Foi solicitado que o instrumento de pesquisa fosse entregue respondido na secretaria acadêmica do CCMB-PUC-SP em 30 dias. Após esta data, ocorreu redistribuição do questionário de forma individual àqueles que não o devolveram até o período predeterminado. Novamente, deu-se 30 dias para que o instrumento de pesquisa fosse respondido e entregue na secretaria acadêmica do CCMB-PUC-SP. Não foi realizada qualquer avaliação para verificar a presença de alguma tendência entre os não respondentes.

Os critérios de inclusão dos sujeitos de pesquisa foram: ser matriculado como aluno de graduação em Medicina do terceiro ano ou ser médico residente do CCMB-PUC-SP.

Os critérios de exclusão foram: não estar regularmente matriculado como aluno de graduação em Medicina do terceiro ano ou como médico residente do CCMB-PUC-SP, não frequentar as atividades acadêmicas/profissionais no período do estudo, não concordar em participar da presente pesquisa.

A escolha dos alunos do terceiro ano de graduação se justifica pelo fato de que nesse momento do curso têm início as atividades de Propedêutica e a frequência ao ambulatório e ao hospital; já os residentes foram escolhidos por integrarem o corpo médico e vivenciarem as situações reais do cotidiano hospitalar em seu aprendizado prático e já responsável da medicina.

$\mathrm{Na}$ análise dos dados foram utilizados testes estatísticos não-paramétricos, levando-se em consideração a natureza das variáveis estruturadas. Para as variáveis qualitativas, foi empregado o teste do qui-quadrado ${ }^{27} \mathrm{com}$ a finalidade de comparar os dois grupos em relação às frequências das várias opções de cada pergunta. Onível de significância adotado para o teste foi de $5 \%$. 
O presente estudo foi aprovado pelo Comitê de Ética em Pesquisa do Centro de Ciências Médicas e Biológicas - Pontifícia Universidade Católica de São Paulo (CCMB-PUC-SP), de acordo com as normas estabelecidas pelo Conselho Nacional de Saúde.

\section{RESULTADOS}

Dos 120 questionários distribuídos, 100 foram respondidos $(83,4 \%)$ pelos residentes, cujas idades variaram de 24 a 34 anos (média de 29,5 anos), sendo 60 do sexo masculino e 40 do feminino. Quarenta e dois por cento trabalham ou já trabalharam em Unidades de Terapia Intensiva (UTI) por um período que variou de um mês a dois anos, e 58\% nunca trabalharam nesse ambiente. Quanto à atuação com pacientes terminais, 35\% trabalham ou já trabalharam por um período que variou de um mês a cinco anos, e 65\% nunca vivenciaram essa situação.

Em relação aos acadêmicos, dos 100 questionários distribuídos, 100 foram respondidos (100\%) - 59 mulheres, 41 homens. A idade variou de 20 a 38 anos (média de 22,9 anos). Acreditamos que a discrepância entre as porcentagens de adesão dos dois subgrupos se deve principalmente à maior proximidade (afinidade) dos autores deste estudo com os acadêmicos.

Os dados referentes à percepção do paciente quanto a seu estado de saúde são descritos a seguir. A maioria dos entrevistados ( $\mathrm{R}-88 \%$ e A-92\%) acha importante que o paciente saiba de sua doença, qualquer que seja sua gravidade. Sessenta e dois por cento dos residentes e $68 \%$ dos alunos concordam em que os enfermos devam ter pleno entendimento de sua enfermidade. Quando questionados se o paciente, sabendo de sua doença grave, piora seu estado, a maioria ( $\mathrm{R}-63 \%$; $\mathrm{A}-52 \%$ ) apontou que sim. A minoria (R-9\%; A - 10\%) acredita que os doentes não têm conhecimento de sua doença antes de serem formalmente informados (Tabela 1).

\section{Tabela 1}

Você acredita que o paciente sabe de sua doença grave antes de ser formalmente informado?

\begin{tabular}{lcc}
\hline Resposta & Alunos (n) & Residentes (n) \\
\hline Sim, quase todos & 21 & 36 \\
Alguns poucos & 53 & 53 \\
Não, não sabem & 10 & 9 \\
Não tenho convicção & 16 & 2 \\
sobre isso & & \\
\hline
\end{tabular}

Nota: $\mathrm{p}=0,0019$.
Quanto à opinião dos respondentes sobre o envolvimento que o médico deve manter com o paciente-família diante da morte e em situações de pacientes terminais, a maioria ( $\mathrm{R}-62 \%$; A-86\%) acha que é responsabilidade do médico dar a notícia de uma doença terminal. Trinta e oito por cento (R) e 14\% (A) acreditam que esta função deva ser realizada por psicólogos, religiosos ou outros profissionais. Quando questionados a respeito do nível de intensidade afetiva do médico frente ao paciente considerado terminal, a maioria apontou grau moderado como ideal (R-58\%; A-56\%). Vinte por cento (R) e $26 \%$ (A) se posicionaram a favor de um envolvimento extremamente intenso ou muito intenso; envolver-se com pouca intensidade ou não se envolver correspondeu a $22 \%$ (R) e a $18 \%(\mathrm{~A})$.

O nível de participação do médico e do acadêmico nos debates para a tomada de decisões quanto ao tipo de tratamento a ser instituído também foi abordado pela pesquisa. A maioria ( $\mathrm{R}-$ $66 \%$; A - 95\%) pouco, raramente ou nunca participou destes encontros ( $p=0,0000)$. Nesse quesito, a resposta positiva permitiu aos respondentes indicar quais profissionais participaram do debate, sendo que em $72 \%$ dos casos outros médicos estavam presentes; em 10\%, psicólogos; em 2\%, assistentes sociais; em $6 \%$, professores e alunos; em $12 \%$, enfermeiros; em $10 \%$, familiares; e em $6 \%$, pacientes. A Tabela 2 inclui a opinião dos respondentes sobre a eutanásia.

Tabela 2

Você é a favor da eutanásia?

\begin{tabular}{lcc}
\hline Resposta & Alunos (n) & Residentes (n) \\
\hline Sim, a pedido do paciente & 42 & 25 \\
Sim, a pedido da família & 9 & 6 \\
Sim, indicada pelo médico & 7 & 4 \\
Não & 24 & 40 \\
Não tenho opinião formada & 18 & 25 \\
\hline
\end{tabular}

Nota: $\mathrm{p}=0,0281$.

No que concerne ao preparo pessoal para lidar com a morte e o processo do morrer, a maioria dos respondentes $(\mathrm{R}-70 \%$; $\mathrm{A}-$ $54 \%$ ) se julga apta a enfrentar a circunstância. Trinta por cento (R) e $46 \%$ (A) disseram que provavelmente ou certamente não estão preparados para a situação. A Tabela 3 mostra os resultados obtidos quanto ao nível de formação dos entrevistados com relação à temática proposta. 
Tabela 3

Durante o curso de graduação médica, você acha que houve preparo teórico, prático e individual para lidar com a morte e o morrer?

\begin{tabular}{lcc}
\hline Resposta & Alunos (n) & Residentes (n) \\
\hline Certamente sim & 5 & 24 \\
Provavelmente sim & 45 & 16 \\
Provavelmente não & 28 & 28 \\
Certamente não & 22 & 32 \\
\hline
\end{tabular}

Nota: $\mathrm{p}=0,0000$.

Nessa questão, as causas das possíveis falhas apontadas pelos respondentes foram, principalmente, falta de debates, de preparo prático, de vivência com pacientes terminais, de disciplinas específicas, de psicologia médica, de acompanhamento psicológico dos alunos e o fato de a formação do médico estar voltada para salvar vidas. Os resultados percentuais com relação ao significado da morte para cada um dos respondentes estão na Tabela 4. Tentou-se, assim, traçar um perfil da sua representação para a população de estudo.

Tabela 4

O que a morte representa para você?

\begin{tabular}{lcc}
\hline Itens selecionados & Alunos (n) & Residentes (n) \\
\hline Morte como um fim & 22 & 10 \\
$\begin{array}{l}\text { Morte como um fim de um } \\
\text { ciclo }\end{array}$ & 51 & 48 \\
Morte como transição & 32 & 32 \\
$\begin{array}{l}\text { Morte como perda } \\
\text { A morte faz parte da vida, é } \\
\text { natural }\end{array}$ & 57 & 34 \\
$\begin{array}{l}\text { Início de uma nova vida } \\
\text { Morte como mistério, enigma }\end{array}$ & 14 & 56 \\
$\begin{array}{l}\text { Sentimento de culpa, } \\
\text { impotência, fracasso }\end{array}$ & 10 & 18 \\
Outro & 23 & 20 \\
\hline
\end{tabular}

Nota: Foi facultado ao entrevistado indicar mais de uma opção como resposta.
Os resultados das questões referentes ao perfil dos entrevistados quanto a suas vivências, desejos e atitudes diante de situações que envolvem a terminalidade foram demonstrados. No ambiente domiciliar, a maioria ( $\mathrm{R}-84 \%$; $\mathrm{A}-78 \%$ ) declarou que pouco frequentemente, raramente ou nunca conversa com seus familiares sobre a morte e as decisões diante do morrer. As Tabelas 5 e 6 demonstram os resultados encontrados para as outras questões propostas.

\section{Tabela 5}

Caso você tivesse uma doença grave (irrecuperável) e apresentasse uma parada cardiorrespiratória, desejaria ser ressuscitado?

\begin{tabular}{lcc}
\hline Resposta & Alunos (n) & Residentes (n) \\
\hline Certamente sim & 33 & 20 \\
Provavelmente sim & 27 & 2 \\
Provavelmente não & 25 & 32 \\
Certamente não & 15 & 46 \\
\hline
\end{tabular}

Nota: $\mathrm{p}=0,0000$.

Tabela 6

Um familiar seu mostra o desejo de não ser ressuscitado se na velhice enfrentasse uma doença grave. Nessas circunstâncias, se ele sofresse uma parada cardiorrespiratória, você iniciaria a reanimação?

\begin{tabular}{lcc}
\hline Resposta & Alunos (n) & Residentes (n) \\
\hline Certamente sim & 29 & 15 \\
Provavelmente sim & 26 & 23 \\
Provavelmente não & 33 & 28 \\
Certamente não & 12 & 34 \\
\hline
\end{tabular}

Nota: $\mathrm{P}=0,0014$.

As descrições das respostas referentes ao caso clínico estão na Tabela 7 e se verificou diferença estatística entre os grupos estudados ( $\mathrm{p}=0,0065)$. Nesta mesma questão, foi solicitado aos participantes que opinassem se durante a internação haveria necessidade de conversar com o paciente e seus familiares para sa- 
ber suas opiniões a respeito da conduta a ser adotada frente a uma eventual parada cardiorrespiratória. A maioria ( $\mathrm{R}$ - 78\%; A $-73 \%$ ) apontou que tal prática é importante.

\section{Tabela 7}

Caso clínico - Paciente do sexo masculino, com 63 anos, apresentando diagnóstico de insuficiência cardíaca por miocardiopatia isquêmica, com fração de ejeção de $20 \%$. Internado na UTI, em centro médico sem condições de transplante cardíaco, sem resposta ao tratamento clínico, dependente de dobutamina e ventilação mecânica por 30 dias. Caso esse paciente apresentasse parada cardiorrespiratória, você iniciaria as técnicas reanimatórias?

\begin{tabular}{lcc}
\hline Resposta & Alunos (n) & Residentes (n) \\
\hline Certamente sim & 36 & 20 \\
Provavelmente sim & 31 & 30 \\
Provavelmente não & 27 & 30 \\
Certamente não & 6 & 20 \\
\hline
\end{tabular}

Nota: $\mathrm{p}=0,0065$.

\section{DISCUSSÃO}

Vida e morte se articulam no jogo existencial do ser humano. Dentre todos os seres vivos, apenas o homem tem consciência de sua finitude. Angustiados pelas pulsões de início e fim, os indivíduos estão habituados a dar realce às causas fortuitas da morte (velhice, acidentes, doenças), diminuindo sua necessidade de um fato causal, negando, dessa forma, sua inevitabilidade ${ }^{28}$. O pensar a morte, encará-la em sua essência, é algo penoso para o homem e expõe lembranças remotas de perdas, dor do luto e receio de um futuro misterioso e incerto ${ }^{9}$. Os profissionais de saúde tendem a não se defrontar com a realidade inexorável da morte, fato este que passa a ser fonte de sofrimento, constituindo um tema tabu, que procuram evitar.

Neste contexto, muitos médicos, em cumplicidade ou não com os familiares, resistem em informar ao paciente sua verdadeira situação, quer explícita (por meio da omissão do diagnóstico) ou implicitamente (com a utilização de termos técnicos incompreensíveis), engendrando a nefasta incomunicação médico-paciente: restringe-se do paciente algo que é seu de direito, o que gera uma relação frágil, calcada na desconfiança do enfermo em relação ao seu cuidador ${ }^{14}$, além de infração ética.
No presente estudo, verificou-se que essa tentativa de omissão da verdade pode ser frustrada: para $36 \%$ dos médicos e $21 \%$ dos estudantes, quase todos os pacientes percebem a gravidade de sua doença, mesmo sem terem sido formalmente informados, embora a maioria (53\%) pense que apenas alguns pacientes têm esta percepção (Tabela 1).

Cabe ressaltar que, de acordo com o Código de Ética Médi$\mathrm{ca}^{29}$, está vedado ao médico:

Deixar de informar ao paciente o diagnóstico, o prognóstico, os riscos e objetivos do tratamento, salvo quando a comunicação direta ao mesmo possa provocar-lhe dano, devendo, nesse caso, a comunicação ser feita ao seu responsável legal. (Código de Ética Médica, cap. V, art. 59, 2006)

Os resultados deste estudo vão ao encontro desse artigo, ao constatarem que, para a maioria dos entrevistados $(\mathrm{R}-62 \%$; $\mathrm{A}-$ $68 \%$ ), o paciente deve ter pleno conhecimento da sua doença, independentemente de sua gravidade, e que cabe ao médico a responsabilidade de informar ao doente um diagnóstico desfavorável. Entretanto, observou-se um decréscimo significativo ( $\mathrm{p}=$ $0,0006)$ na porcentagem de respostas entre os dois grupos $(R-$ $62 \%$; A - 86\%), mostrando a tendência de os residentes desejarem outorgar sua obrigação de dar a notícia de uma doença terminal a outros profissionais. Esta mudança de postura ocorre provavelmente pela vivência dos residentes com tais situações, fato que ainda não é realidade para os alunos.

No entanto, existem casos em que o paciente almeja não ser comunicado sobre sua real situação, preferindo permanecer na ignorância. Para Kübler-Ross ${ }^{30}$, é desumano forçar um paciente a aceitar a realidade quando ele diz não estar pronto para ouvi-la. Os resultados deste estudo estão de acordo com este posicionamento, já que, para a maioria dos respondentes, em algumas situações, o conhecimento da gravidade da doença poda contribuir para piorar o estado de saúde do paciente.

É inevitável a presença de sofrimento e dor neste ambiente insalubre que afeta emocionalmente o profissional da saúde. Tal aspecto torna a medicina uma das ciências que mais expõem o homem a seus conflitos essenciais, a seus mais categóricos limites. Na prática médica, as pessoas se encontram marcadamente expostas a pressões e desgastes. Ao agir diante das condições que a dor suscita, o médico, constantemente, é confinado às questões relacionadas ao sofrimento, as quais rompem seu equilíbrio, desestabilizando-o emocionalmente ${ }^{1,31,32}$.

O permanente convívio do médico em ambientes de elevada sobrecarga emocional requer do profissional uma formação que 
não lhe é oferecida na graduação ${ }^{17}$. Existe uma ideologia, incorreta, segundo a qual durante os anos acadêmicos os discentes devem ser "protegidos" do desenvolvimento emocional que tal condição provoca, enfatizando-se, assim, somente procedimentos técnicos em detrimento da formação humana. De acordo com Coelho ${ }^{17}$, a complexidade dos parâmetros relacionados à origem e permanência de processos mórbidos traz obstáculos de penosos equacionamentos, exigindo uma formação sólida e madura, capaz de considerar as possibilidades e os limites da prática específica.

A vulnerabilidade emocional pode prejudicar o médico no desenvolvimento de suas atividades diante das necessidades do enfermo, além de atingir a ele mesmo. Essa situação pode levar a uma sobrecarga, denominada Síndrome de Burnout, uma das consequências mais marcantes do estresse profissional, que se caracteriza por exaustão emocional e física, despersonalização e diminuição da capacidade de realização pessoal. Refere-se a um tipo de tensão emocional crônica de pessoas que cuidam de maneira muito intensa de outros ${ }^{33,34}$. Além disso, como demonstraram os estudos de Martins $^{35}$, Remick ${ }^{36}$ e Young ${ }^{37}$, há uma elevada taxa de dependência química, depressão e suicídio entre os médicos.

Há um envolvimento profissional que Cassorla ${ }^{38}$ denominou distância ótima: envolver-se o necessário com o doente, garantindo-lhe assistência humana e, concomitantemente, proteger-se da contaminação da situação para manter-se hígido e com capacidade de atuação. Tal condição deveria ser treinada no ambiente acadêmico e não simplesmente acontecer durante os anos de profissão, com possíveis males para o médico e o paciente.

A análise dos resultados apresentados neste estudo vai ao encontro do posicionamento destes autores e mostra homogeneidade entre os dois grupos estudados. Verificou-se que a maioria ( $\mathrm{R}-58 \%$; A - 56\%) das respostas dadas foi para a opção moderada, ensejando um resguardo do médico, e $20 \%$ (R) e 26\% (A) defendem um envolvimento mais intenso, quer seja extremamente intenso ou muito intenso. Apesar da subjetividade, evidencia-se que $80 \%$ dos entrevistados se sentem envolvidos no drama do doente, sendo este um motivo de alerta.

A compreensão das vicissitudes pelas quais passam os pacientes e seus familiares frente ao diagnóstico de uma doença incurável é de fundamental importância para o entendimento de seus males. Diversos autores apresentaram as fases do processo do luto ${ }^{30,39,40,41}$. Classicamente, Kübler-Ross ${ }^{30}$ propôs seis estágios: (1) negação e isolamento - negação inicial, estágio em que o indivíduo se mostra assombrado num primeiro instante, enjeita acreditar no diagnóstico e recusa aceitar que algo esteja errado; (2) raiva - afloração dos sentimentos de raiva, revolta e ressenti- mento; (3) barganha-o paciente procura negociar com médicos, familiares, amigos e Deus com o intuito de, em troca da cura, cumprir promessas; (4) depressão - o enfermo não consegue negar mais sua doença, surge um sentimento de grande perda em que é possível observar sintomas clínicos de depressão; (5) aceitação - o paciente reconhece que a morte é inevitável e aceita a universalidade da experiência; (6) esperança - o doente deixa uma lacuna pela qual algum fator novo possa vir a modificar a situação iminente da morte.

Nem sempre o paciente passará por todos esses estágios; podem não ocorrer alguns ou existir fixação em outros. O tempo de duração das fases está intimamente relacionado ao desenvolvimento emocional do enfermo. Frequentemente, os familiares sofrem as mesmas etapas de adaptação do luto que o doente terminal percorreu. Muitas vezes, o paciente em estágio inicial de negação projeta sentimentos inconscientes de raiva e hostilidade em relação ao seu cuidador, complicando a relação médico-paciente. Cabe ao médico compreender esse acontecimento e conduzi-lo de forma adequada.

É notória a dificuldade dos médicos em consentirem a terminalidade de seus doentes, o que dificulta a tomada de decisão sobre a manutenção ou não de um tratamento, principalmente para o médico recém-formado, pela falta de vivência em tais situações. Como encontrado neste estudo, 58\% dos residentes nunca trabalharam em UTI e apenas 35\% tiveram experiência com pacientes terminais. A participação frequente em discussões para tomar esse tipo de decisão provavelmente traria ao aluno e ao residente uma formação diferenciada para sua vida profissional do ponto de vista não só técnico como também psicológico. Isso não foi observado pelos respondentes desta amostra, em que $66 \%$ (R) e 90\% (A) participaram de tais discussões com baixa frequência ou nunca participaram.

Outra questão importante nesse tipo de abordagem se refere à eutanásia. Koch ${ }^{42}$ mostrou que cerca de $25 \%$ dos médicos e estudantes de Medicina definem como eutanásia a interrupção de um tratamento. Cabe ressaltar que eutanásia (grego $\varepsilon u=$ advérbio bem / / regular, justamente / / com bondade, com benevolência / / felizmente; $\theta$ avaто $\varsigma=$ morte) significa prática pela qual se busca abreviar, sem dor e sofrimento, a vida de um doente reconhecidamente incurável.

A distinção entre eutanásia ativa (positiva ou direta) e passiva (negativa), segundo Pessini ${ }^{43}$, é que a primeira se trata de uma “ação médica pela qual se põe fim à vida de uma pessoa enferma, seja isso um pedido do paciente ou uma ação feita à revelia da vontade deste" (p. 23). Já a segunda "não consistiria numa ação médica, mas na omissão, isto é, a não aplicação de uma terapia médica com 
a qual se poderia prolongar a vida da pessoa enferma" (p. 24). Aeutanásia de duplo efeito ocorre quando a morte é acelerada em função de procedimentos médicos que não objetivam o êxito letal, mas o alívio do sofrimento de um paciente ${ }^{3,44}$.

De acordo com o Código de Ética Médica ${ }^{29}$ :

O médico deve guardar absoluto respeito pela vida humana, atuando sempre em benefício do paciente. Jamais utilizará seus conhecimentos para gerar sofrimento físico ou moral, para o extermínio do ser humano, ou para permitir e acobertar tentativa contra sua dignidade e integridade. (Código de Ética Médica, Capítulo I, artigo 6, 2006)

É vedado ao médico: “utilizar, em qualquer caso, meios destinados a abreviar a vida do paciente, ainda que a pedido deste ou de seu responsável legal". (Código de Ética Médica, Capítulo V, artigo 66, 2006).

Vale lembrar que distanásia (סı = dificuldade, privação / /

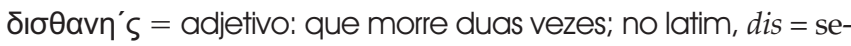
paração e negação) é a manutenção da vida por meio de procedimentos desproporcionais (obstinação terapêutica), conduzindo a um morrer prolongado repleto de sofrimento ${ }^{44}$.

Ortotanásia refere-se à boa morte, sem sofrimento, sem tratamentos desproporcionais, e, consequentemente, ao não prolongamento do morrer. Assim, a interrupção de um procedimento julgado fútil deve ser aceita como ortotanásia e não eutanásia ${ }^{19,45}$.

Recorrendo à recente resolução do Conselho Federal de Me$\operatorname{dicina}^{47}$ :

Na fase terminal de enfermidades graves e incuráveis é permitido ao médico limitar ou suspender procedimentos e tratamentos que prolonguem a vida do doente, garantindo-lhe os cuidados necessários para aliviar os sintomas que levam ao sofrimento, na perspectiva de uma assistência integral, respeitada a vontade do paciente ou de seu representante legal. (Resolução do Conselho Federal de Medicina, nº 1.805).

Os resultados apresentados na Tabela 2, com relação à prática da eutanásia, mostraram divergência de opiniões entre os dois grupos de estudo ( $p=0,0281$ ). Constatou-se que 35\% (R) e $58 \%$ (A) são favoráveis à prática da eutanásia seja a pedido do paciente ( $\mathrm{R}-25 \%$; $\mathrm{A}-42 \%)$, da família ( $\mathrm{R}-6 \%$; A - 9\%) ou indicada pelo médico $(\mathrm{R}-4 \%$; $\mathrm{A}-7 \%)$. A falta de opinião a respeito do assunto foi de $25 \%$ (R) e $18 \%$ (A) da amostra, sendo talvez re- flexo da falta de vivência dos respondentes com esse tipo de situação clínica. Isto possivelmente seria minimizado pelo aumento da participação em debates e discussões sobre as decisões tomadas em casos críticos e pela introdução da disciplina de Bioética nos cursos de Medicina. De acordo com Pessini ${ }^{46}$ :

Bioética [...] é o estudo interdisciplinar dos problemas criados pelo progresso biomédico (seja em nível de relação individual, institucional ou mesmo de estrutura social), sua repercussão na sociedade e seu sistema de valores. (p. 37)

Na mesma obra, o autor define as questões abordadas pela Bioética: "início e fim da vida humana e as que se situam numa área intermediária" (p. 46). Seus princípios fundamentais se referem a: "beneficência, autonomia, justiça, a alteridade, a sacralidade da vida humana, qualidade de vida, natureza e pessoa, o homem como senhor da natureza e a definição de natureza humana". Fato também evidente é que a maioria dos entrevistados ( $\mathrm{R}-60 \%$; A - 76\% - Tabela 2), em princípio, não concorda com a legislação em vigor, que, segundo o Código Penal Brasileiro, considera eutanásia como homicídio ou auxílio ao suicídio ${ }^{48}$.

Outro aspecto abordado neste estudo foi o questionamento sobre a percepção quanto às suas possibilidades para lidar com pacientes terminais. Dos respondentes, $70 \%$ (R) e $54 \%$ (A) das respostas foram afirmativas, sendo que $60 \%$ (R) e $50 \%$ (A) disseram não ter recebido formação teórico-prática suficiente durante o curso de graduação (Tabela 3). Ainda apontaram como prováveis falhas a falta de vivência, de debates, de apoio psicológico sistemático e a formação do médico voltada para salvar vidas e não para perder pacientes.

Resultados semelhantes foram encontrados no estudo realizado por Cataldo ${ }^{40}: 43,8 \%$ dos alunos não se sentiam preparados para lidar com tal situação, 0,7\% não responderam e 56,5\% alegaram se sentir preparados. O mesmo grupo, questionado em relação à aprendizagem sobre a temática "morte/morrer", propõe contato induzido com pacientes terminais e aulas teóricas e práticas sobre o assunto.

Schliemann ${ }^{49}$ enfatizou que a formação dos profissionais de saúde tem se mostrado inapropriada para lidar com a situação da morte e do morrer. Diz que, do ponto de vista técnico, o tema não é discutido na graduação e, no trabalho prático, em geral, é desqualificado.

Além disso, o ensino médico sobre esse assunto ficou estagnado por muitos anos e somente nos últimos tempos tem se defrontado com a necessidade de readaptações curriculares. As escolas médicas, de forma geral, têm a graduação calcada no relatório Flexner 
(1902), que doutrinava o ensino com base numa visão biocêntrica/tecnocêntrica. O corpo humano era dividido em partes, e a presença de doença era encarada como disfunção biológica. Assim, o objetivo das universidades era graduar especialistas em doença, e não capacitá-los para cuidar de doentes, reduzindo a visão do indivíduo como um todo. A atenção atual presente na solução de questões de saúde denota a incorporação de um conceito mais amplo na educação elementar. Os novos currículos devem ser desenvolvidos com fundamentação antropocêntrica e serem capazes de formar profissionais que possam contribuir para o bem-estar físico, psíquico e social dos enfermos ${ }^{50}$.

Diversos estudos mostraram o benefício existente no ensino formal de estudantes e/ou médicos no que diz respeito à abordagem e a condutas a adotar diante de pacientes terminais ${ }^{51-55}$.

Para tanto, Carson ${ }^{56}$ propôs a introdução de uma disciplina que ministrasse as ciências humanas aos graduandos, apresentando discussões filosóficas e aspectos morais nas experiências com os doentes.

Branday ${ }^{57}$ debateu o ensino de traços humanísticos nas ciências médicas e afirmou que o discente é mais bem formado observando exemplos corretos de ações efetuadas por professores que já aceitaram a existência da morte emocionalmente.

Barnard et al. ${ }^{58}$ apontaram as necessidades essenciais para o cuidado paliativo dos pacientes: ter habilidade na comunicação, na entrevista e no manejo de sintomas comuns; demonstrar domínio psicológico, sociológico, espiritual e cultural das bases do processo de morrer; cabedal ético; autorreflexão e autoconhecimento.

A necessidade de humanização no ensino acadêmico tem conduzido à reestruturação de alguns cursos de Medicina, com a incorporação da Psicologia Médica, por exemplo. Na Faculdade de Medicina de Sorocaba - Centro de Ciências Médicas e Biológicas da Pontifícia Universidade Católica de São Paulo, até 2005, havia no currículo a disciplina Psicologia Geral e do Desenvolvimento, que discutia a concepção do aluno sobre a morte, apresentava conceitos teóricos sobre o tema, propunha atividades práticas a fim de sensibilizar os discentes para uma atitude mais globalizada frente ao paciente e ajudá-los a lidar melhor com seus sentimentos. Com a reestruturação da metodologia de ensino desta instituição e a introdução do Ensino Baseado em Problemas (PBL - Problem Based Learning), extinguiu-se tal disciplina. O que se espera é que as atividades tutoriais do PBL permitam garantir, além do conhecimento técnico-científico, reflexões nas quais os tutores e consultores capacitados dividam suas experiências e promovam o desenvolvimento da temática nas esferas teórica, pessoal e prática com os alunos.
O questionamento do significado da morte para cada um dos participantes deste estudo foi colocado com abertura para mais de uma possibilidade de resposta. Os resultados (Tabela 4) destacam a aceitação da morte como um processo natural e como o fim de um ciclo, corroborando a opinião de Calam ${ }^{59}$, para quem é preciso que o ser humano reconheça a morte como uma fase natural de sua existência e, aceitando-a como tal, aprenda a conviver com ela. Isto foi ainda ratificado pelos residentes (78\%), que demonstraram tendência a não desejarem ser ressuscitados se sofressem parada cardiorrespiratória e fossem portadores de doença irrecuperável. No entanto, $60 \%$ dos alunos mostraram opinião divergente, contrariando a aceitação da morte como um continuum da vida (Tabela 5). Essa postura foi reafirmada, com diferença estatisticamente significativa entre os grupos, quando questionados sobre a conduta que teriam diante da situação clínica acima descrita, com envolvimento de um familiar (Tabela 6).

Como se pode observar no presente estudo, o tema morte e decisões diante do morrer não fazem parte dos diálogos domiciliares cotidianos para a maioria dos entrevistados. Apenas 12\% (R) e 16\% (A) o fazem com frequência, indicando que a temática ainda não é discutida com naturalidade.

As questões finais do questionário tiveram por objetivo verificar a posição dos respondentes diante de situações que envolvem doenças graves com ou sem perspectivas de cura. Diante de um indivíduo em estado terminal irreversível que sofre parada cardiorrespiratória, impõe-se um dilema no sentido da conduta a ser tomada: reanimar ou não. Pelo exposto, está claro que, quando há evidências clínicas concretas de que o enfermo não se beneficiaria com o procedimento, não existem indicações éticas para aceitá-lo como ato terapêutico. Assim, a decisão deve estar calcada nas condições clínicas e prognósticas de cada paciente, bem como na discussão prévia do cuidador com os familiares e, quando possível, com o próprio doente.

Os resultados encontrados neste estudo mostraram igualdade de atitudes dos dois grupos analisados, favorecendo as manobras de ressuscitação em pacientes com diagnóstico de afecção incurável (Tabela 7).

Finalmente, enfocando a participação do paciente e/ou familiares diante das atitudes a adotar frente à terminalidade, observou-se igualdade entre os respondentes, que concordaram em considerar suas opiniões no momento de optar por uma conduta clínica. Embora a maior parte dos estudantes e dos médicos admita ser correta a conversa com o paciente e familiares sobre a opinião a respeito de um evento possível, ou seja, a necessidade de reanimação, observou-se que do ponto de vista ético e médi- 
co-legal 33\% dos estudantes e 50\% dos médicos (Tabela 7) não iniciariam manobras de reanimação. Por outro lado, tal porcentagem se altera quando há um grau de parentesco entre o estudante/médico e o paciente, apontando o enorme conflito na tomada da mesma decisão e como esta repercute em questões sociais e legais, o que demonstra nitidamente a falta de preparo de estudantes e de médicos para a situação.

Somente com uma formação adequada e decisões corajosas da sociedade por meio de seus representantes nos poderes de Estado é que se conseguirá aliviar os ombros do médico do enorme peso que a vivência, no isolamento de seus próprios juízos, tem que fazer na arena em que o morrer e a morte se colocam.

\section{CONCLUSÃO}

O Homem tem direito à morte como tem direito à vida. Morrer é um processo humanamente tão importante quanto nascer e viver.

\section{Jurgen Moltmann}

Tendo por base a compreensão dos dados obtidos neste estudo e na literatura, é possível sustentar os seguintes aspectos da relação médico-paciente-morrer-morte, sob as perspectivas dos médicos recém-formados e dos estudantes de Medicina: (1) a relação médico-paciente terminal é fonte de elevada carga de dúvidas quanto às condutas profissional e pessoal; (2) não existe adequada capacitação para lidar com a questão da terminalidade do ser humano; (3) há dúvidas éticas e legais frente aos procedimentos a executar diante do doente terminal; (4) há desconforto no trato com o enfermo, em especial na tomada de decisões com o doente e seus familiares, idealmente compartilhada com outros profissionais, mas praticamente feita de maneira solitária pelo médico recém-formado; (5) apesar da falta de preparo na graduação médica, os recém-formados se julgam onipotentemente preparados para lidar com a terminalidade; (6) a diferença de perfil encontrada em algumas situações entre os dois grupos de estudo possivelmente resulta da falta de vivência prática por parte dos estudantes; (7) nas situações propostas, é frequente o aparecimento da omissão de socorro, com infração do Código de Ética Médico e da lei.

Considerando-se a complexidade e as várias interfaces de abordagem desse tema, ressalta-se a necessidade de introduzir nos currículos de graduação em Medicina o ensino formal teórico-prático da tanatologia desde o início do curso. O estudo sobre a morte, suas causas e fenômenos, e a compreensão dos mecanismos psicológicos existentes na superação de seus efeitos sobre a mente humana criariam um espaço legítimo onde se poderia desenvolver paulatinamente a capacitação para enfrentar os dilemas da morte e do morrer.

\section{REFERÊNCIAS}

1. Siqueira-Batista R, Batista RS. De como filosofar é aprender a morrer: o pensamento de Michel de Montaigne como pressuposto na discussão sobre a morte e o processo de morrer na prática médica. Cad Saude Colet. 2002;10(1):9-18.

2. Dastur F. A morte. Ensaio sobre a finitude. Rio de Janeiro: Difel; 2002.

3. Siqueira-Batista R, Schramm FR. A filosofia de Platão e o debate bioético sobre o fim da vida: interseções no campo da saúde pública. Cad Saude Publica. 2004;20(3):855-65.

4. Heidegger M. Être et temps. Paris: Gallimard; 1986.

5. Montaigne M. Ensaios. São Paulo: Nova Cultura; 2000.

6. Spinosa B. Ethic. Paris: Gallimard; 1954.

7. Hegel GWF. Fenomenologia do espírito. Petrópolis: Vozes; 1992.

8. Kovács MJ. Atitudes diante da morte: visão histórica, social e cultural. In: Kovács MJ, org. Morte e desenvolvimento humano. São Paulo: Casa do Psicólogo; 1992. p.29-48.

9. Zaidhaft, S. Morte e formação médica. Rio de Janeiro: Francisco Alves; 1990.

10. Rodrigues JC. Tabu da morte. Rio de Janeiro: Achiamé; 1983.

11. Morin E. O homem e a morte. Lisboa: Europa-América; 1970.

12. Carvalho VA. A vida que há na morte. In: Bromberg MHPF, (Org.). Vida e morte: laços de existência. São Paulo: Casa do Psicólogo; 1996. p.35-75.

13. Job JRPP. Aspectos da educação e práticas médicas. In: Vannucchi A, (Org.). Diálogos Interuniversitários: vida e morte, educação e saúde. São Paulo: Arte e Ciências; 2002. p.170-8.

14. Quintana AM, Cecim PS. O preparo para lidar com a morte na formação do profissional de medicina. Rev Bras Educ Med. 2002;26(3):204-10.

15. Lasch C. The culture of narcisim. New York: Norton; 1978.

16. Eizirik CL, Polanczyk GV, Eizirik M. O médico, o estudante de medicina e morte. Rev AMRIGS. 2000;44(1-2):50-5.

17. Coelho MO. Relação médico-paciente e a morte. São Paulo; 2001. Doutorado [Tese] - Pontifícia Universidade Católica de São Paulo.

18. Kovács MJ. Os Profissionais de saúde e educação e a morte. In: Kovács MJ, org. Educação para a morte: desafio na formação de profissionais de saúde e educação. São Paulo: Casa do Psicólogo; 2003. p.23-70.

19. Moritz RD. O efeito da informação sobre o comportamento dos profissionais de saúde diante da morte. Florianópolis; 
2002. Doutorado [Tese] - Universidade Federal de Santa Catarina

20. Da Nova JLL, Bezerra Filho J, Bastos LAM. Lição de anatomia. Interface Comum Saúde Educ. 2000;4(6):87-96.

21. Ariès P. História da morte no ocidente: da idade média à atualidade. Rio de Janeiro: Francisco Alves; 1997.

22. Simon R. O complexo tanatolítico justificando medidas de psicologia para estudantes de medicina. Bol Psiquiatr. 1971;4(4):113-5.

23. Sapir M. La formation psychologique du médecin. Paris: Payot; 1972.

24. Fliess R. The autopsie encumbrance: some remarks on na unconscious interference with the managment of the analytic situation. Int. J. Psycholanal. 1954;35:8-12.

25. Rhodes-Kropf J, Carmody SS, Seltzer D, Redinbaugh E, Gadmer N, Block SD; et al. "This is just too awful; I just can't believe I experienced that...": medical students' reactions to their "most memorable" patient death. Acad Med. 2005;80(7):634-40.

26. D'Assumpção EA. Perfil da atitude médica diante do paciente terminal. Rev Bras Cir. 1994;84(4):159-62.

27. Siegel S. Nonparametric statistics. New York: McGraw-Hill; 1988.

28. Nabarro SW. Morte: dilemas éticos do morrerr. Arq Cons Regional Med do Pr. 2006;23(92):185-202.

29. Brasil. Conselho Federal de Medicina. Lesgilação. Código de Ética. Resolução CFMnº 1.246/88 de 8 dejan. 1988. [documento na intenrnet]. Brasília. Disponível em: http:/ / www.portalmedico.org.br/novoportal/index5.asp.

30. Kübler-Hoss E. Sobre a morte e o morrer. São Paulo: Martins Fontes; 1998.

31. Machado MH coord. Os médicos no Brasil: um retrato da realidade. Rio de Janeiro: Fiocruz; 1997.

32. Selingmann S. Desgaste mental no trabalho dominado. Rio de Janeiro: Ed. UFRJ; 1994.

33. Shimizu HE. As representações sociais dos trabalhadores de enfermagem não enfermeiros sobre o trabalho em UTI em um hospital escola. São Paulo; 2001. Doutorado [Tese] - Universidade de São Paulo.

34. Tamayo MR. Relação entre a síndrome de Burnout e os valores organizacionais no pessoal de enfermagem de dois hospitais públicos. Brasília; 1997. Doutorado [Tese] - Universidade de Brasília.

35. Martins LAN. Residência médica: um estudo prospectivo sobre as dificuldades na tarefa assistencial e fontes de es- tresse. São Paulo; 1994. Doutorado [Tese] - Universidade Federal de São Paulo.

36. Remick RA. Refractory depressive illness in pshysicians. Columbia Med J. 1988;40(4):153-5.

37. Young JJ, Ursanp RJ, Baally RE, Mcneil DS. Consultation to a clinic following suicide. Am J Orthopsychiatry. 1989;59(3):473-6.

38. Cassorla RMS. Psicanálise e morte. In: Kovács MJ, org. Vida e morte: laços da existência. São Paulo: Casa do Psicólogo; 1996. p.83-94.

39. Bowlby J. Formação e rompimento de vínculos afetivos. São Paulo: Martins Fontes; 1997.

40. Cataldo NA; Araujo PA. A morte e o morrer no hospital escola: comunicação preliminar. Rev Bras Educ Med 1996;20(esp):26-8.

41. Parkes CM. Luto: estudo sobre a perda da vida adulta. São Paulo: Summus; 1998.

42. Koch KA. A linguagem da morte: euthanatos et mors. Clínicas de Terapia Intensiva. 1996;1(1):1-13.

43. Pessini L. Morrer com dignidade. Aparecida: Santuário; 1990.

44. Martin LM. Eutanásia e distanásia. In: Costa SIF, (Org.). Iniciação à bioética. Brasília, Conselho Federal de Medicina; 1998. p.171-92.

45. Kovács MJ. Autonomia e o direito de morrer com dignidade. [periódico na internet]. Rev Bioet (Impr.). 1998:6(1). [acesso em 20 nov. 2006]; Disponível em: http:/ / www.portalmedico.org.br/revista/ind1v6.htm.

46. Pessini L, Barchifontaine CP. Problemas atuais da bioética. São Paulo: Loyola; 1994.

47. Brasil. Conselho Federal de Medicina. Resolução CFM nº 1805/2006, de 28 de novembro de 2006. [documento na internet]. Brasília. [acesso em 18 mar. 2007]. Disponível em: http:/ / www.portalmedico.org.br/resolucoes/cfm/2006/1805_2006.htm.

48. Borges RCB. Eutanásia, ortotanásia e distanásia: breves considerações a partir do biodireito brasileiro. [documento na internet]. Jus navegandi. [acesso em 20 out. 2006]. Disponível em:htpp://jus2.uol.com.br/doutrina/texto.asp?id=7571..

49. Schliemann AL. Estudo sobre a concepção de morte em alunos de Medicina. São Paulo; 1997. Doutordo [Tese] Pontifícia Universidade Católica de São Paulo.

50. Pessini L. Humanização da dor e sofrimento humanos no contexto hospitalar. Rev Bioética. 2002;10(2):51-72. 
51. Ury WA, Arnold RM, Tulsky JA. Palliative care curriculum development: a model for a content and process-based approach. J Palliat Med. 2002;5(4):539-48.

52. Ury WA,Berkman CS, Weber CM, Pignotti MG, Leipzig RM. Assessing medical students' training in end-of-life communication: a survey of interns at one urban teaching hospital. Acad Med. 2003;78(5):530-7.

53. Sullivan AM, Lakoma MD, Billings JA, Peters AS, Block SD, PCEP Core Faculty. Teaching and learning end-of-life care: evaluation of a faculty development program in palliative care. Acad Med 2005;80(7):657-68.

54. Ratanawongsa N, Teherani A, Hauer KE. Third-year medical students' experiences with dying patients during the internal medicine clerkship: a qualitative study of the informal curriculum. Acad Med. 2005;80(7):641-7.

55. Han PK, Arnold RM. Palliative care services, patient abandonment, and the scope of physicians' responsibilities in end-of-life care. J Palliat Med. 2005;8(6):1238-45.

56. Carson RA. The formation of medical imagination. Rev Bras Educ Med. 2000;24(1):31-35.

57. Branday JM. The dying patient-teaching doctors to care. West Indian Med J. 1996; 45:45-7.

58. Barnard D, Quill T, Hafferty FW, Arnold R, Plumb J, Bulger R, et al. Preparing the ground: contributions of the pre- clinical years to medical education for care near the end of life. Working group on the pre-clinical years of the national consensus conference on medical education for care near the end of life. Acad Med. 1999;74:499-505.

59. Calam B, Far S. Discussions of "code status" on a family practice teaching ward: what barriers do family physicians face? CMAJ. 2000;14(163):1255-9.

\section{CONTRIBUIÇÃO DOS AUTORES}

Todos os autores realizaram o levantamento bibliográfico da literatura nacional e internacional relevante ao estudo; redação, coleta e análise dos dados e revisão final do trabalho.

\section{CONFLITO DE INTERESSES}

Declarou não haver.

\section{ENDEREÇO PARA CORRESPONDÊNCIA}

Gustavo Nader Marta

Rua Frei Caneca, 750 - apto 3052

Conceição - São Paulo - SP

CEP: 01307-000

E-mail: gnmarta@uol.com.br 